\title{
Quatro pontos para reflexão sobre a iniciação científica
}

\author{
Four points to ponder in scientific initiation ${ }^{1}$
}

\author{
Luciana Karine de Souza ${ }^{2}$
}

\section{RESUMO}

Universidades e agências de fomento à pesquisa investem em bolsas de Iniciação Científica (IC) anualmente, fornecendo oportunidades para pesquisadores juniors e seniors selecionarem estudantes para a atividade remunerada em IC. A IC é uma atividade importante para a formação do estudante universitário, com reflexos construtivos para seu futuro profissional. Ao mesmo tempo, o pesquisador recebe auxílio para o andamento de suas pesquisas e, em início de carreira, está se preparando para futuras orientações em pós-graduação. O presente texto apresenta, com base nas leituras realizadas, em experiências e observações livres ou relatos informais, quatro pontos para reflexão com respeito à IC. Sem pretender esgotar a discussão, o objetivo com este relato é compartilhar as considerações elaboradas e incentivar aqueles graduandos que tiverem interesse em se envolver na atividade de IC e aos recém-doutores para que abriguem alunos nesta atividade importante à formação profissional, seja ela na pesquisa ou na prática.

Palavras-chave: Iniciação científica. Orientação. Graduação.

\begin{abstract}
Universities and research funding agencies invest on scientific initiation (SI) grants every year, providing opportunities to junior and senior researchers to choose students for a paid activity on SI. SI is an important activity for the university students' studies, with constructive outcomes to his(her) professional future. At the same time, the researcher receives aid for the development of his(her) work and, at the beginning of his(her) career, he(she) is preparing for future supervising on a graduate level. This paper presents four points to consider with respect to SI, based on bibliography studied, on experiences and free observations or informal talks. With no intent to close the discussion on the topic, the goal of this paper is to share ideas and encourage undergraduate students that may be interested on SI and also encourage junior researchers to embrace students on this important activity for their professional path, either chosen to be professional or academic.
\end{abstract}

Keywords: Scientific initiation. Supervising. Undergraduate studies.

\footnotetext{
1 "Scientific initiation" is an activity, usually supported by grants given by Brazilian institutions to university or high school students, aimed to develop interest in scientific work.

${ }^{2}$ Docente e pesquisadora em desenvolvimento social e da personalidade no Depto. de Psicologia e no Mestrado Interdisciplinar em Lazer da Universidade Federal de Minas Gerais (UFMG).
}

Esta obra foi licenciada com uma Licença Creative Commons - Atribuição 3.0 Não Adaptada. 


\title{
1 INTRODUÇÃO
}

As universidades e agências de fomento à pesquisa (Conselho Nacional de Desenvolvimento Científico e Tecnológico - CNPq, Coordenação de Aperfeiçoamento de Pessoal de Nível Superior - CAPES, fundações estaduais de amparo à pesquisa, etc.) investem em bolsas de Iniciação Científica (IC) anualmente, fornecendo oportunidades para pesquisadores juniors e seniors selecionarem estudantes para a atividade remunerada em IC. Em alguns cursos de graduação, por exemplo, há o aproveitamento de créditos curriculares para a IC orientada por um professor do curso. Assim, o estudante consegue registrar oficialmente em seu currículo a experiência em IC. Não raro há casos de orientação científica voluntária, na qual o estudante busca aprendizado, conhecimento e experiência sem remuneração ou créditos para o currículo.

O CNPq $\left(2006^{3}\right)$ oferece o Programa Institucional de Bolsas de Iniciação Científica (PIBIC), cujos objetivos são:

\begin{abstract}
despertar vocação científica e incentivar novos talentos potenciais entre estudantes de graduação; contribuir para reduzir o tempo médio de titulação de mestres e doutores; propiciar à instituição um instrumento de formulação de política de iniciação à pesquisa para alunos de graduação; estimular uma maior articulação entre a graduação e pós-graduação; contribuir para a formação de recursos humanos para a pesquisa; contribuir de forma decisiva para reduzir o tempo médio de permanência dos alunos na pósgraduação; estimular pesquisadores produtivos a envolverem alunos de graduação nas atividades científica, tecnológica e artística-cultural; proporcionar ao bolsista, orientado por pesquisador qualificado, a aprendizagem de técnicas e métodos de pesquisa, bem como estimular o desenvolvimento do pensar cientificamente e da criatividade, decorrentes das condições criadas pelo confronto direto com os problemas de pesquisa.
\end{abstract}

Assim, além do intuito de desenvolver o interesse pela atividade científica e instrumentar o graduando para tal, os objetivos da agência citada incluem uma relação estreita entre graduação e pós-graduação e com a formação de grupos de pesquisa.

Szczepanik (2006) faz uma análise aprofundada da obra do filósofo Thomas Kuhn e seu posicionamento sobre o aprendiz em ciência. Embora T. Kuhn não tenha proposto um programa de educação científica, a leitura atenta de Szczepanik notou pontos importantes destacados pelo filósofo. Para este, a educação científica 
contempla a adoção de certas regras, mas especialmente um comprometimento entre os membros da comunidade científica. Dessa forma, depreende-se que a atividade científica é essencialmente coletiva. A educação científica também deve estimular a leitura dos clássicos mencionados nos manuais e livros-texto apresentados aos alunos de IC. Além disso, educar para a ciência é promover a criticidade e evitar a doutrinação, ao mesmo tempo em que cultivar o desenvolvimento de um comportamento profissional. Szczepanik (2006) também destaca que, na IC, a relação orientador-orientando passa primeiramente por uma relação mais caracterizada por verticalidade, para mais tarde tornar-se mais horizontal, elencando o aprendiz à condição de colega.

Fava de Moraes e Fava (2000) analisam a IC em suas vantagens e imprecisões. De um lado, os autores apontam como vantagens a fuga da rotina universitária propiciada pela inserção em um grupo de pesquisa e em projetos científicos. Mais especificamente, destacam o desenvolvimento da leitura crítica, da autonomia amparada pelo orientador, do espírito de equipe, da desenvoltura ao falar em público, da postura madura e com discernimento úteis à carreira práticoprofissional (fora da pesquisa), da perda do medo ao novo e ao diferente, da competitividade saudável, e da criatividade. De outro lado, Fava de Moraes e Fava (2000) alertam para possibilidades como: o uso da IC com o objetivo único de formar para a pós-graduação; do professor simpático que não orienta e não contribui para a formação do aluno; e do orientador que utiliza dos bolsistas como mão de obra barata para atividades exclusivamente manuais e/ou de auxílio burocrático.

De forma interessante, Pitta et al. (2000) investigaram o impacto da experiência em IC sobre os estilos cognitivos de estudantes de Psicologia de uma universidade pública do interior de São Paulo. Segundo os autores, estilo cognitivo é a forma pela qual o indivíduo organiza e processa experiências e informações, e de como orienta soluções e toma decisões. Quatro dimensões de estilos cognitivos são consideradas por Pitta et al. (2000): campo dependente versus independente; impulsividade de resposta versus reflexividade; convergência de pensamento versus divergência; e holista versus serialista. Comparando bolsistas com não-bolsistas, os autores observaram que todos os bolsistas apresentaram predomínio do estilo divergência de pensamento (criatividade, fluência, pouca sociabilidade), a maioria apresentou o estilo reflexividade de resposta (ponderação prévia às respostas), e 
menos convergência e impulsividade que os não-bolsistas. Os participantes do estudo admitiram que a atividade de IC interferiu em seus estilos cognitivos no sentido de acentuá-los apenas, mas não de modificá-los. Interessantemente, os participantes atribuíram este resultado ao orientador, ao trabalho em equipe e às atividades em IC.

Um estudo exploratório foi conduzido por Bastian et al. (2000) com 82 estudantes universitários do Curso de Psicologia da Pontifícia Universidade Católica do Rio Grande do Sul. Os autores investigaram o conhecimento dos alunos sobre a pesquisa científica. A premissa adotada foi a de que, em geral, os psicólogos não valorizam o trabalho científico. Constatado o pouco conhecimento dos alunos sobre a pesquisa científica e as oportunidades da universidade nesse sentido, os autores conduziram grupos com os participantes para promover consciência crítica e fornecer esclarecimentos e informações importantes para uma escolha pela IC fundamentada e informada. Para Bastian et al. (2000), a formação do aluno deve promover uma interação séria e compromissada com a pesquisa, e a informação sobre a possibilidade de envolvimento em projetos de pesquisa através da IC deve ser divulgada logo no início do curso para os alunos.

Há experiências brasileiras frutíferas em IC. Na Enfermagem, por exemplo, Alencastre et al. (1996) relatam bons resultados a partir da experiência com IC sem bolsa, com uma disciplina obrigatória da grade curricular sobre conhecimento científico, e com a participação de alunos de iniciação em eventos científicos - esta última admitida por orientadores e orientandos como atividade importante que prepara o estudante como apresentador de trabalho científico.

Já Mazon e Trevizan (2001) salientam a importância da interdisciplinaridade na IC, relatando uma experiência frutífera envolvendo os cursos de Enfermagem e de Administração. Para os autores, a interdisciplinaridade é uma abordagem intensa e extensa ao fenômeno em tela, com melhor condição de lidar com sua particularidade e a complexidade. Além disso, o trabalho interdisciplinar, para melhor abordar o objeto de pesquisa de interesse, requer o trabalho coletivo, em equipe, no qual as trocas estabelecidas permitem um concomitante aperfeiçoamento dos pesquisadores envolvidos. Para Mazon e Trevizan (2001), tanto a Enfermagem como a Administração dependem do esforço interdisciplinar. Os ganhos com a experiências transcorrida envolveram a reconstrução do conhecimento através da 
ação conjunta entre os profissionais, proporcionada pela real integração atingida pela experiência de IC vivenciada.

Nas Ciências Sociais, é digno de nota a análise realizada por Villas-Bôas (2003) sobre a relação entre a evasão de estudantes e a atividade de IC. Segundo a autora, a participação no programa de IC do curso de Ciências Sociais colaborou para reduzir a evasão e para colaborar para a qualidade da graduação. Os bolsistas destacaram como positivas a presença da bolsa como auxílio financeiro, a amplitude de relações e aquisição de conhecimento crítico.

Na Química, Queiroz e Almeida (2004) acompanharam em profundidade a experiência em IC de graduandos. Os autores observaram que, dentre outros aspectos, os estudantes destacaram a quebra da rotina universitária trazida pelo envolvimento na bolsa, a oportunidade de questionar conceitos consolidados sobre ciência e o papel do cientista, e o envolvimento direto na construção de conhecimento científico.

Ainda na Química, e também na Engenharia Química, Zakon (1989) parte dos depoimentos de estudantes de graduação e de docentes-pesquisadores destes dois cursos para discutir as qualidades desejáveis na IC. Tanto para o pesquisador como para o estudante, é desejável que o aluno de IC tenha interesse pelo trabalho científico desenvolvido, responsabilidade e disponibilidade de tempo para nele se envolver. Interessantemente, aluno e professor destacam que o orientador de IC deve ser acessível, sincero, amigo e motivador para a atividade científica em geral; ao mesmo tempo, a qualidade de "ser amigo" não é citada pelos professores como algo desejável em um aluno de IC, e por estes é a característica menos citada. Em sua explanação, Zakon (1989) argumenta que o entrosamento e a comunicabilidade são verdadeiramente muito importantes para o sucesso tanto da relação alunoorientador, como do andamento do projeto. O autor também salienta o trabalho de equipe com "espírito de equipe", num ambiente de cooperação, tranquilidade e confraternização, com papéis e responsabilidades definidos claramente a cada um. Zakon (1989) também relata procedimentos adotados com os alunos de IC em Química e Engenharia Química, como o treinamento/ensaio com a equipe toda de apresentações de trabalhos para congressos científicos, num contexto onde os erros podem acontecer com tranquilidade, as orientações passadas com apoio coletivo e a motivação fomentada e disseminada a todos que assistem ao ensaio. Além disso, o 
autor cita o treinamento para a escrita científica, com pequenas cartilhas como "Sugestões para uma boa redação" e "Instruções para a apresentação de textos técnicos".

Na Medicina, Oliveira, Alves e Luz (2008) relataram sobre a participação em IC de estudantes deste curso provenientes de quatro estados brasileiros. Oitenta e quatro por cento dos alunos pesquisados defenderam a obrigatoriedade da IC na formação médica. Para os autores, o principal empecilho à pouca participação de estudantes de Medicina em programas de IC é a falta de estímulo por parte da instituição, em especial, daquelas de natureza privada. Oliveira, Alves e Luz (2008, p. 313) observam que

um pressuposto e requisito essencial à boa prática médica é a habilidade para pensar cientificamente e usar o método científico, o que significa, em consequência, que o médico está submetido a uma necessidade de adquirir continuamente novas informações científicas e novos conhecimentos.

$\mathrm{Na}$ experiência relatada pelos autores, percebe-se a relação estreita entre ciência e profissão, outro aspecto a ser lembrado no trabalho em IC.

Pires (2009) descreve uma pesquisa realizada com 127 egressos de IC de uma universidade pública da Bahia. A autora conduziu oito entrevistas com professores-pesquisadores que foram bolsistas de IC na universidade baiana pesquisada. A autora tece algumas reflexões com base nas respostas dos egressos à experiência em IC. Pires (2009) chama à atenção à diferença entre tratar o aluno de IC como mão de obra para a carreira do orientador ou como um aprendiz para a profissão acadêmico-científica. Também traça recomendações às agências de fomento no que tange sua política de pesquisa e de formação do futuro pesquisador, bem como faz um alerta à instituição de ensino envolvida na pesquisa no que diz respeito à sua política de pesquisa.

$\mathrm{Na}$ área da Psicologia, Marques (1996) investigou a experiência de 12 egressos em Psicologia com bolsa de iniciação científica. Os ex-bolsistas apontaram aspectos positivos da experiência, como o desenvolvimento de um modo de raciocinar mais abrangente e o aprendizado na convivência com os colegas de equipe; como ponto negativo, indicaram a dissociação entre as teorias estudadas em sala de aula e as abordadas nos projetos de pesquisa, bem como experiências de IC sem contato com teorias ou bibliografia que fundamenta o projeto. 
Leme (2001) também estudou o impacto da IC na formação do psicólogo. A partir de uma abordagem qualitativa, a autora coletou depoimentos de professores e de alunos de IC do Curso de Psicologia da Universidade de São Paulo. Os orientadores destacaram o contraste percebido entre as atividades de orientação e de ensino, posto que na primeira é possível desenvolver uma relação mais próxima com o aluno, o que é benéfico para sua aprendizagem e para a atividade em IC. Os estudantes participantes mencionaram pontos positivos e negativos associados à IC. Dentre os negativos, os bolsistas citaram uma espécie de especialização precoce por conta do trabalho com objetos de estudo muito específicos ao projeto de pesquisa desenvolvido. Também mencionaram a variação nos estilos de orientação dos professores, dos quais uns tratavam o aluno como mero executor de tarefas, deixando-o menos autônomo e preparado, enquanto outros proporcionavam uma orientação muito "solta", sem diretrizes, deixando o aluno perdido. Os alunos ressaltaram como ponto negativo a ausência de divulgação sobre a oportunidade de envolvimento com IC, a exemplo do que constataram Bastian et al. (2000). No trabalho de Leme (2001), como pontos positivos os bolsistas relataram: o desenvolvimento de uma relação mais flexível com o conhecimento, especialmente através da postura crítica, conduzindo a um outro modo de pensar; a promoção da autonomia de da postura ativa diante do conhecimento e dos problemas científicos; e a relação de trocas estabelecida com o orientador.

Pesquisadores que atualmente são bolsistas de produtividade e orientadores de mestrado e doutorado dedicaram-se, durante a graduação, à IC com pioneiros da pesquisa científica brasileira. Em continuidade, os bolsistas de produtividade foram orientadores de IC de recém-doutores que atualmente vem ocupando novas vagas nas universidades federais, especialmente naquelas criadas mais recentemente (por exemplo, a Universidade Federal do Recôncavo Baiano). Um caso que ilustra esta cadeia de orientações é o da Professora Dra. Angela Maria Brasil Biaggio, falecida em 2003, pioneira na pesquisa em Psicologia no Brasil (SOUZA; GAUER, 2008).

A IC é uma atividade importante para a formação do estudante universitário, com reflexos construtivos para seu futuro profissional. Ao mesmo tempo, o pesquisador recebe auxílio para o andamento de suas pesquisas e, em início de carreira, está se preparando para futuras orientações em pós-graduação. Ao final, todos se beneficiam com a atividade. 
O presente texto apresenta, com base nas leituras realizadas, nas experiências das autoras e em observações livres ou relatos informais, quatro pontos para reflexão com respeito à IC. O objetivo está organizado em duas fases: a) identificar e organizar os textos disponíveis sobre experiências em IC com estudantes universitários; e b) discutir quatro pontos importantes envolvidos na IC. Sem pretender esgotar a discussão, espera-se compartilhar as considerações elaboradas e incentivar graduandos que se interessem pela IC e recém-doutores, estes últimos para que abriguem alunos nesta atividade importante à formação profissional, seja ela na pesquisa ou na prática.

\section{O PAPEL DO ORIENTADOR EM INICIAÇÃO CIENTIFICA}

Sem dúvida o orientador é um dos grandes responsáveis por uma IC bem sucedida. O aluno é um aprendiz que necessita de orientação, incentivo, discussão, correção, quase totalmente dependente das atribuições dadas pelo orientador e o investimento deste em seu aprendizado.

Pode-se identificar três tipos de orientador: o autossuficiente, o superamigo, o visitante. O orientador autossuficiente pouco confia no potencial do orientando, achando-o constantemente imaturo. Apenas delega atividades fáceis, como a aplicação coletiva de questionário, ou a organização de materiais, ou a confecção de painéis para congressos com base em textos já prontos. Por vezes o orientador realiza por si próprio certas atividades que deveriam ser realizadas pelo estudante sob sua orientação. Esta ausência de confiança no aluno de IC é prejudicial para este na medida em que não o permite realizar atividades desafiadoras que enriqueçam sua aprendizagem e proporcionem o avanço. Ao final, o aluno desmotiva-se e pode permanecer na bolsa apenas pela recompensa financeira.

Outra faceta do orientador autossuficiente é sua tendência em utilizar do aluno de IC como simples mão de obra para a pesquisa. A mesma desmotivação pode surgir no estudante, além de passar a ele uma visão empobrecida do que seja o trabalho em pesquisa. Esta postura do orientador vem sendo criticada tanto por 
professores como por estudantes (FAVA DE MORAES; FAVA, 2000, LEME, 2001, PIRES, 2009), e serve de alerta para o recém-doutor que pretende orientar em IC.

O orientador superamigo, por sua vez, é altamente amigável com seus orientandos de IC. No entanto, ele exagera nas relações amistosas a ponto de não conseguir estabelecer uma relação de orientador-orientando. O contexto de trabalho é de coleguismo generalizado entre alunos e orientador, sem que este exerça qualquer nível de autoridade ${ }^{4}$ sobre os orientandos. O superamigo raramente consegue cobrar tarefas e prazos dos estudantes, procurando evitar autoridade por temer perder a afeição do orientando. Os estudantes adoram o orientador, mas não aprendem habilidades importantes para sua formação em IC e nem tem explorado seu potencial. Neste contexto, alguns alunos se perdem pelo caminho, desmotivados pela falta de desafios e atividades instigantes na IC. Esta postura "solta" do orientador é criticada pelos estudantes do trabalho de Leme (2001) e através das reflexões propostas por Fava de Moraes e Fava (2000).

O orientador visitante raramente encontra seus orientandos, pouco interagindo com eles, resumindo-se a distribuir tarefas mensais. Este orientador é altamente ausente, visitando seu próprio laboratório entre viagens a congressos e outros compromissos. Sabe menos da pesquisa conduzida do que os alunos de IC que, na verdade, a estão conduzindo praticamente sozinhos. Nesse caminho, os alunos às vezes acabam assumindo atividades e responsabilidades que caberiam ao orientador. Isso se torna bastante complicado em situações problemáticas que surgem no decorrer das pesquisas, como erros metodológicos, fragilidades nas análises, descuidos na coleta de dados. Estas situações são oportunidades de aprendizado para o aluno de IC, visto que o orientador pode demonstrar como corrigi-las e evitá-las. No entanto, o orientador visitante pouco acompanha sua equipe de IC, mas dela possivelmente cobrará diante de problemas que envolvam a investigação científica conduzida.

Os textos disponíveis sobre a experiência em IC destacam a relação de proximidade necessária entre orientador e orientando. No estudo de Leme (2001), os orientadores ressaltaram a diferença de proximidade com o orientando de IC e com o aluno em sala de aula, sendo a primeira mais gratificante para o professor. Pires (2009) também valoriza a relação orientador-orientando como uma das peças- 
chave para um bom trabalho em IC. Zakon (1989) encontrou, na fala de bolsistas, que o orientador deve ser acessível, sincero, amigo e motivador, ao passo que os orientadores participantes do estudo não acreditam que a amizade seja uma relação necessária no empreendimento em IC. Por fim, Szczepanik (2006) destaca que a relação adequada para uma boa experiência em IC, tanto para o orientador como para o aluno, é uma relação de coleguismo.

Assim, como se pode perceber, parecem consensuais algumas características ou habilidades que um orientador de IC deve apresentar: manter contato direto com o aluno, acompanhando de perto suas atividades (sugere-se pelo menos quinzenalmente) e auxiliando-o quando necessário; proporcionar atividades desafiadoras; fornecer feedback sistematicamente; incentivar a participação em eventos científicos e publicações; estar disponível, mesmo diante de uma agenda apertada; promover aprendizagem ativa através de diálogo e debate, ouvindo o estudante e estimulando-o a participar; estimular para o aperfeiçoamento constante e o aprendizado com os erros; agir eticamente e exigir postura ética, servindo de modelo profissional e valorizando o aluno em seu desempenho.

\section{AS ATIVIDADES EM IC}

Há distintas atividades a serem proporcionadas pela IC. Possibilitar a iniciação em ciência é colocar o estudante em contato com os passos da(s) pesquisa(s) conduzida(s) pela equipe do orientador. Nesse sentido, o aluno deve aprender sobre: elaboração da pergunta de pesquisa, objetivo(s), relevância e justificativa do trabalho, revisão bibliográfica dos temas abordados, estudo da base teórica que fundamenta as hipóteses ou expectativas, estratégia de pesquisa (delineamento), procedimentos metodológicos (escolha de instrumentos, coleta e análise dos dados), elaboração de resumo para submissão a evento científico e posterior apresentação oral e gráfica do trabalho, escrita de relatório de pesquisa, e escrita de manuscrito para submissão a periódico científico.

Quando possível, a escrita de manuscrito sobre a pesquisa proporciona ao estudante participar de contribuição direta à produção científica publicada. Segundo 
uma estudante de IC em sua autoavaliação, "Quando terminamos o artigo, senti um carinho e um orgulho pelo produzido" (sic) $)^{5}$. É nessa direção que Zakon (1989) defende a participação do aluno de IC nas publicações através da promoção do desenvolvimento de habilidades de escrita científica como parte das atividades de pesquisa do aluno.

Algumas das atividades citadas anteriormente aparecem nos depoimentos de estudantes que atuaram em IC, de orientadores e de autores preocupados com a qualidade do trabalho em IC. Szczepanik (2006) argumenta sobre a importância de estimular o aluno de IC à leitura de autores clássicos associados ao tema da pesquisa, no lugar de apenas tomarem contato com manuais e livros-texto. Já Marques (1996) relata casos de experiências em IC sem o contato com a fundamentação teórica da pesquisa ou a bibliografia pertinente referente ao objeto de pesquisa abordado, o que é empobrecedor ao trabalho em IC. Interessantemente, o estudo de Fava de Moraes e Fava (2000) e de Queiroz e Almeida (2004) evidenciam que os alunos percebem o envolvimento em IC como uma quebra da rotina universitária. Nesse sentido, a IC pode inclusive servir como elemento motivador para a permanência do universitário na instituição, como argumentado por Villas-Bôas (2003) em sua constatação sobre a redução da evasão associada à oferta de IC.

No caso de pesquisas já em andamento, o aluno de IC pode ficar sem a experiência de acompanhar os passos da investigação já trilhados. Nesse caso, pode-se solicitar à equipe que relate os passos tomados, fornecer leitura de embasamento para o estudante recém-chegado, ou mesmo simular atividades para que o bolsista tenha uma experiência aproximada com o que já foi empreendido pela equipe. Outra oportunidade é envolver o aluno nos projetos de pesquisa dos pósgraduandos, que normalmente se encontram em fases distintas. Isso proporcionaria ao aluno de IC conhecer procedimentos de pesquisa já realizados no projeto ao qual sua bolsa se vincula.

Uma maneira de se proporcionar uma experiência integral em IC é permitir que o estudante crie seu próprio projeto de pesquisa. Tratar-se-ia de uma verdadeira imersão na experiência científica. No entanto, ao recém-chegado é importante um

$5 \mathrm{O}$ artigo ao qual a aluna se refere foi publicado em periódico científico Qualis B2 em Psicologia em 2010.

Cad. de Pesq. Interdisc. em Ci-s. Hum-s., Florianópolis, v.12, n.101, p.219-236, ago/dez 2011 
período de adaptação, integração à equipe de pesquisa, e o estabelecimento da confiança e compromisso para ingressar em um empreendimento científico sozinho.

Ele demanda criatividade, autonomia, responsabilidade, iniciativa, comprometimento, comportamento profissional, motivação e persistência (FAVA DE MORAES; FAVA, 2000, LEME, 2001, QUEIROZ; ALMEIDA, 2004, SZCZEPANIK, 2006, ZAKON, 1989). A respeito destas disposições, os próprios egressos as incluem como necessárias ao trabalho científico ou como produtos da experiência em IC. O desenvolvimento da postura crítica diante do conhecimento científico é relatado em Queiroz e Almeida (2004), Villas-Bôas (2003), Pitta et al. (2000), Szczepanik (2006), Fava de Moraes e Fava (2000) e Leme (2001), e o desenvolvimento de um raciocínio mais abrangente e flexível é referido em Marques (1996) e Leme (2001). Também o orientador precisa estar disponível para a entrada de um novo projeto em seu cronograma.

Um destaque deve ser dado a algumas das atividades de IC. A participação em eventos científicos é uma oportunidades na qual o aluno de IC encontra seus pares, troca experiências e vivências, bem como se expõe ao público do evento. Apresentar o trabalho em congresso é colocar o estudante diante de sua comunidade científica, de uma audiência de pares com atitude crítica, científica e com genuíno interesse no avanço do trabalho. É ainda ter contato com cientistas de outras instituições de ensino e associações científicas, bem como com outros alunos de IC e seus projetos, e com o público que assiste ao trabalho e a ele reage, fazendo perguntas ou fornecendo sugestões. Alencastre et al. (1996) e Zakon (1989) também argumentam sobre o papel importante da participação em evento científico na experiência em IC.

\section{BOLSISTA OU VOLUNTÁRIO: VANTAGENS E DESVANTAGENS}

O tema da bolsa em IC traz à tona a questão da motivação. A recompensa financeira é uma motivação externa interessante para o estudante de graduação (VILLAS-BÔAS, 2003). Isso é verdadeiro especialmente naqueles casos em que o 
indivíduo ou não tem condições de trabalhar porque o currículo não permite, ou ele estuda em universidade privada.

Curiosamente, nem todo graduando está interessado em receber bolsa pela IC. Não são raros os estudantes que se beneficiariam da bolsa, mas que recusam o vínculo porque acreditam que o compromisso com as atividades de pesquisa seriam muito maiores, assim como as cobranças por parte do orientador e da agência financiadora da bolsa. Nestes casos, bons estudantes tem procurado por IC voluntária, seja em troca de créditos acadêmicos para o currículo (ALENCASTRE et al., 1996), seja pela experiência com pesquisa.

Por vezes o orientador erroneamente acredita que deve exigir o máximo do estudante com bolsa de IC. É este tipo de atitude que afasta candidatos em potencial à experiência em pesquisa, bem como faz com que outros só se envolvam em IC sem bolsa. O compromisso com as atividades não deve ser atrelado à recompensa financeira. É o compromisso com o fazer científico que deve ser fomentado, e o aprendizado reconhecido como a verdadeira recompensa. Um entendimento claro sobre estas questões no momento da seleção do estudante para a bolsa previne contra obstáculos que possam se apresentar nessa direção.

$\mathrm{Na}$ prática, raras são as diferenças entre o aluno com bolsa e o aluno sem bolsa de IC. Há casos, inclusive, de maior disposição, entusiasmo e envolvimento por parte daqueles estudantes sem bolsa. Muito provavelmente há uma sensação de liberdade na ausência da bolsa. Todavia o estudante não visualiza que, mesmo sem recompensa financeira, ele não está livre de responsabilidades com a forma como conduz as atividades de pesquisa, seu relacionamento com a equipe, e sua postura ética em geral como auxiliar de IC e como pessoa.

\section{APOIO INSTITUCIONAL E RECURSOS}

O trabalho em IC, bem como a condução da pesquisa que o abarca, necessita de um conjunto de recursos. Afora os recursos específicos ao projeto de pesquisa, como softwares específicos, por exemplo, que precisam ser adquiridos por causa do projeto em si, há materiais e condições necessárias para que seja possível 
abrigar um aluno de IC na equipe. Será necessário, no mínimo, um computador conectado à Internet e a uma impressora. Muitas vezes um gravador digital será preciso, especialmente na condução de entrevistas. O espaço físico adequado também é um elemento importante, fornecendo concretamente um lugar ao estudante no laboratório.

Um aspecto importante dentro da questão dos recursos de trabalho ao aluno de IC é ajudá-lo a cultivar o cuidado e a preservação destes materiais. Isto é importante especialmente nos casos de recursos públicos, quando muitas vezes as pessoas entendem que não é necessário o uso cuidadoso e responsável com recursos públicos. Além disso, será importante estimular o aluno a compartilhar os recursos com os colegas de trabalho, bem como ser solidário com colegas que necessitam de auxílio para usar os materiais e equipamentos.

Um ponto destacado nos textos analisados é a queixa de estudantes sobre a ausência de amplitude na divulgação sobre as oportunidades de trabalho em IC (LEME, 2001). Outra questão avaliada é o desconhecimento sobre o investimento em pesquisa por parte dos calouros, como demonstrado por Bastian et al. (2000). Assim, as instituições de ensino superior precisam diversificar suas formas de divulgação dos editais para bolsas de IC, assim como a oferta de vaga sem bolsa necessita ser amplamente informada à comunidade discente.

O apoio institucional é fundamental para a oferta de atividade de IC para os estudantes (PIRES, 2009). No entanto, no contexto universitário privado a questão dos recursos para pesquisa pode ser um desafio (OLIVEIRA; ALVES; LUZ, 2008). Quando o professor conquista espaço para desenvolver pesquisa científica, o passo seguinte é conseguir estudantes para orientar em IC. Os recursos podem ser escassos, mas o pesquisador vai precisar, acima de tudo, de mostrar à instituição o uso necessário dos materiais e equipamentos. Isto pode ser alcançado quando o projeto de pesquisa tem relação com as disciplinas lecionadas pelo professor. Projetos de pesquisa que envolvem iniciativas de extensão universitária de natureza comunitária também tornam a solicitação do professor mais atraente para a instituição privada. Nestes casos, envolver contrapartidas comunitárias, especialmente conectadas com as necessidades da população local, é um fator importante não apenas para elevar a relevância social do projeto de pesquisa, mas também para inserir o aluno de IC na realidade social a seu entorno. 


\section{CONSIDERAÇÕES FINAIS}

Este texto procurou levantar algumas reflexões sobre a iniciação científica em estudantes universitários. Quatro pontos foram abordados: o papel do orientador, as atividades em IC, o uso de bolsa de estudos ou voluntariado, e o apoio institucional.

A discussão realizada não contempla todos os pontos envolvidos na orientação em IC, posto que este não era o objetivo do presente trabalho. Quatro aspectos foram eleitos e discutidos, e a literatura empírica encontrada aponta outras questões merecedoras de debate.

Um dos resultados mais esperados da orientação em IC é o interesse do estudante pelo ingresso no mestrado e engajamento na carreira acadêmica. De fato, algumas instituições de ensino exigem, nos relatórios de bolsa de IC, que o aluno se posicione sobre seu interesse em buscar o mestrado. Logicamente, é esperado que o candidato a mestrado com experiência em IC se adapte mais facilmente ao trabalho em stricto sensu e possa desempenhar melhor a função de acompanhar estudantes de IC quando for o caso. De toda forma, nem sempre o mestrado é a escolha do estudante que desempenhou bem na IC.

As habilidades desenvolvidas através do trabalho com IC são também bastante úteis à prática profissional, caso o estudante opte por este caminho. $\mathrm{O}$ trabalho em equipe (MARQUES, 1996, MAZON; TREVIZAN, 2001; SZCZEPANIK, 2006) e, mais do que isso, o espírito de equipe (FAVA DE MORAES; FAVA, 2000, ZAKON, 1989), por exemplo, é uma experiência importante para a qualidade da experiência em IC e para o futuro profissional do aluno.

O raciocínio científico, da mesma forma, pode auxiliar muitos profissionais em suas práticas. A título de exemplo, o psicólogo pode estar mais atento às múltiplas e diferentes variáveis envolvidas nos atendimentos que realiza, e uma preocupação com a avaliação do paciente no início e ao final da psicoterapia também demonstra uma visão metodológica cara e própria do exercício em ciência - no caso, fundamental à atividade em IC. Assim, a experiência com IC permite ao profissional o compromisso com uma prática reflexiva, atenta e preocupada com a eficiência e a eficácia de seus métodos. É esperado, portanto, uma relação próxima entre ciência e profissão (OLIVEIRA; ALVES; LUZ, 2008, PIRES, 2009). 
Outro aspecto importante, e ainda pouco discutido na literatura, é o trabalho interdisciplinar e suas contribuições para o aluno de IC. Mazon e Trevizan (2001) relatam brevemente a experiência compartilhada de IC no trabalho conjunto entre Enfermagem e Administração. Outros exemplos, já com alguma trajetória exitosa, e ainda não relatados na forma de texto científico publicado, vem produzindo resultados bastante gratificantes para orientadores e orientandos. A área interdisciplinar dos Estudos do Lazer é um exemplo, conduzindo pesquisa interdisciplinar, envolvendo estudantes de graduação em IC, e melhor preparandoos tanto para a vida científica como a profissional. Isto porque o lazer é um fenômeno que, por natureza, requer uma abordagem interdisciplinar, e embora outros fenômenos também o requeiram, ele tem sido um dos poucos a gerar tamanho investimento em pesquisa, produção científica publicada e formação em stricto sensu realmente dedicados à interdisciplinaridade.

Espera-se que o presente texto tenha alcançado algumas metas. A primeira foi de identificar e organizar os textos já disponíveis sobre experiências em IC com estudantes universitários. A segunda meta foi discutir quatro pontos importantes da IC. Finalmente, a terceira meta, embora implícita e não anunciada, foi de convidar orientadores e estudantes a refletir mais sobre as práticas e possibilidades em IC, especialmente considerando os obstáculos como oportunidades de aprendizagem e de uso de criatividade. Todo este empreendimento vem pelo bem da ciência mas, sobretudo, pelo desenvolvimento do pensamento científico, criativo e crítico da realidade que nos cerca, seja ela social ou científica. 


\section{REFERÊNCIAS}

ALENCASTRE, M. B. et al. Programa institucional de bolsas de iniciação científica: experiência da Escola de Enfermagem de Ribeirão Preto da Universidade de São Paulo. Revista Latino-Americana de Enfermagem, v.4, n.2, p.229-236, 1996.

BASTIAN, F. S. et al. Despertando o interesse pela pesquisa científica em psicologia. Psico (PUCRS), v.31, n.1, p.123-131, 2000.

CONSELHO NACIONAL DE DESENVOLVIMENTO CIENTÍFICO E TECNOLÓGICO. Programa Institucional de Bolsas de Iniciação Científica - PIBIC. Brasília, 2006. Disponível em: <http://www.cnpq.br/normas/rn_06_017_anexo3.htm>. Acesso em: 12 out. 2010.

FAVA DE MORAES, F.; FAVA, M. A iniciação científica: muitas vantagens e poucos riscos. São Paulo em Perspectiva, v.14, n.1, p.73-77, 2000.

LEME, M. I. da S. Iniciação à pesquisa científica. Psicólogo inFormação, v.5, n.5, p.25-34, 2001.

MARQUES, J. C. O impacto da iniciação científica na formação do psicólogo. Psico (PUCRS), v.27, n.2, p.9-21, 1996.

MAZON, L.; TREVIZAN, M. A. Fecundando o processo da interdisciplinaridade na iniciação científica. Revista Latino-Americana de Enfermagem, v.9, n.4, p.83-87, 2001.

OLIVEIRA, N. A. de; ALVES, L. A.; LUZ, M. R. Iniciação científica na graduação: o que diz o estudante de Medicina? Revista Brasileira de Educação Médica, v.32, n.3, p.309-314, 2008.

PIRES, R. C. M. Formação inicial do professor pesquisador através do Programa PIBIC/CNPq: o que nos diz a prática profissional de egressos? Avaliação (Campinas), v.14, n.2, p.487-514, 2009.

PITTA, K. B. et al. Estilos cognitivos de estudantes de psicologia: impacto da experiência em iniciação científica. Psicologia Escolar e Educacional, v.4, n.2, p.41-49, 2000.

QUEIROZ, S. L.; ALMEIDA, M. J. P. M. de. Do fazer ao compreender ciências: reflexões sobre o aprendizado de alunos de iniciação científica em Química. Ciência \& Educação, v.10, n.1, p.41-53, 2004.

SOUZA, L. K.; GAUER, G. Orientação acadêmica da iniciação científica ao pósdoutorado: o exemplo de Angela M. B. Biaggio (1940-2003). Mosaico: Estudos em Psicologia, v.2, n.1, p.57-63, 2008. 
SZCZEPANIK, G. E. A iniciação científica como forma de aprender a ver o mundo. Aprender (Vitória da Conquista), v.4, n.6, p.153-178, 2006.

VILLAS-BÔAS, G. K. Currículo, iniciação científica e evasão de estudantes de ciências sociais. Tempo Social (USP), v.15, n.1, p.45-62, 2003.

ZAKON, A. Qualidades desejáveis na iniciação científica. Ciência e Cultura:

Revista da Sociedade Brasileira para o Progresso da Ciência, v.41, n.9, p.868877, 1989.

Artigo:

Recebido em: 20/03/2011

Aceito em:14/12/2011 